\title{
Animals positive for Yersinia pestis in Armenia
}

\author{
Ruben Danielyan* \\ National Center for Disease Control and Prevention, Shirak branch, Yerevan, Armenia
}

\section{Objective}

The objective of this study was to determine the species composition of mammals and parasites involved in the epizootic process of plague in Armenia and their geographic distribution.

\section{Introduction}

Plague was first identified in Armenia in 1958 when Y. pestis was isolated and cultured from the flea species $C t$. teres collected from the burrows of common voles in the northwestern part of the country. In the process of digitalizing archived data, a statistical and spatial analysis of the species composition of mammals and parasites involved in the epizootic process of plague between 1958 and 2016 was performed.

\section{Methods}

The plague archives of the NCDCP were exploited. The geographic addresses from which strains of $Y$. pestis were isolated from mammals and their parasite species were analyzed and grouped into 38 administrative regions (Fig.1). For geostatistical analysis, databases were created using Microsoft Excel and converted into a ESRI Geodatabase (Fig.2)

\section{Results}

Data from the especially dangerous pathogen laboratories indicate that 9329 Y. pestis strains were isolated in 27 of the 38 regions of the country with $7022(75 \%)$ of the strains found in just four regions: Abovyan 2597 (28\%), Sisian 1953 (21\%), Martuni 1416 (15\%) and Ashotsk 1056 (11\%) (Fig.3). During this period, plague bacteria were isolated from 17 mammal species including 15 rodents, Mustela nivalis (weasel), and Neomys fodiens (shrew) (Fig.4). Y. pestis was isolated from 22 species of fleas belonging to 11 genera along with two families of ticks. Of the 9329 bacterial isolates, $6540(70.2 \%)$ came from fleas, 2646 (28.3\%) came from mammals and $143(1.5 \%)$ were from ticks (Fig.5).

\section{Conclusions}

In Armenia, the primary mammalian host for $Y$. pestis is the common vole Microtus arvalis from which 2600 isolates (27.9\%) were taken. Flea species from which large numbers of plague bacteria have been isolated include $C t$. teres-3758 (40.3\%), Ct. wladimiri-1262 (13.5\%) and C. caspia-667 (7.1\%).

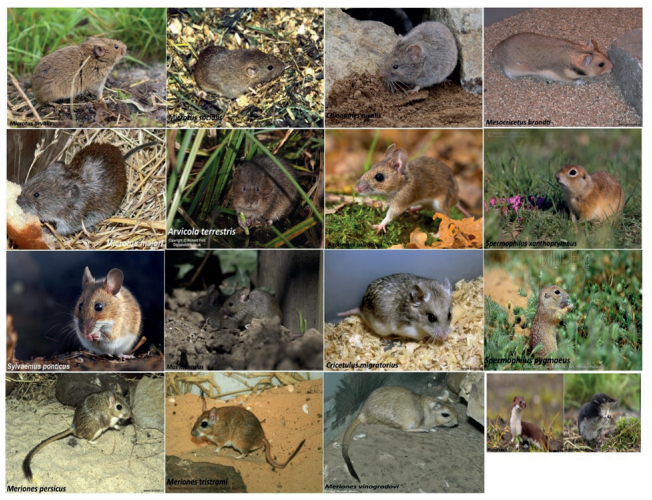

Figure 1. The number of isolated strains of Y.pestis by years.

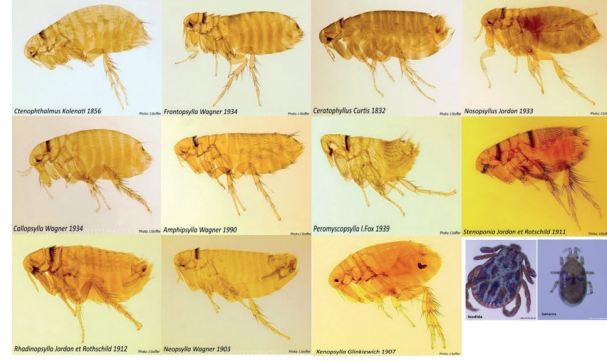

Figure 2. The geostatistical analysis of isolated strains of Y.pestis in Armenia.

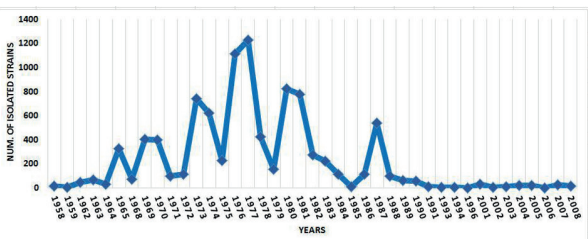

Figure 3. In four regions where was discovered $75 \%$ of $Y$. pestis.

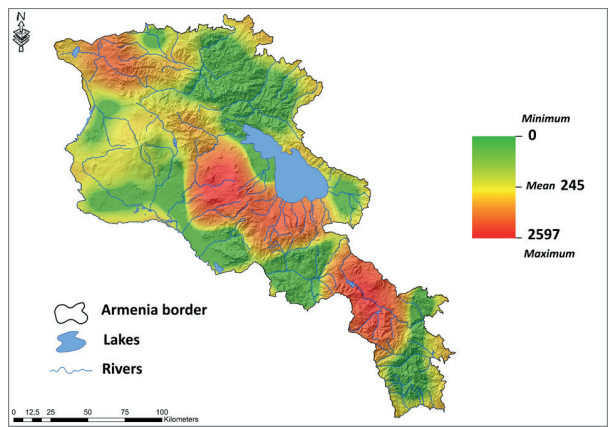

Figure 4 . The 17 species mammals including 15 rodents, weasel and shrew.

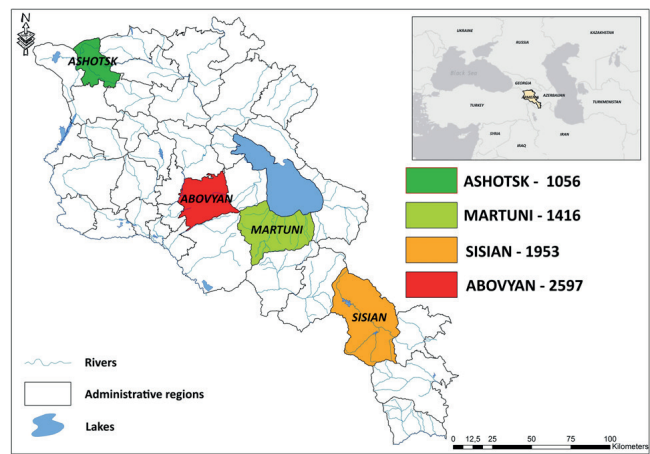

Figure 5. The 11 genera fleas and two families of ticks.

\section{Keywords}

Yersinia pestis; geostatistical analysis; epidemiology

\section{${ }^{*}$ Ruben Danielyan}

E-mail: roubendanielyan@yahoo.com 